\title{
A DEMONSTRAÇÃO DO VALOR ADICIONADO COMO INSTRUMENTO DE MENSURAÇÃO DA DISTRIBUIÇÃO DA RIQUEZA*
}

\author{
JACQUELINE VENEROSO ALVES DA CUNHA \\ Doutoranda em Controladoria e Contabilidade pela FEA-USP \\ E-mail: jvacbr@yahoo.com.br
}

\author{
MAISA DE SOUZA RIBEIRO \\ Professora Doutora do Depto. de Contabilidade da FEARP-USP \\ E-mail: maisorib@usp.br
}

\section{ARIOVALDO DOS SANTOS}

Professor Livre-docente do Depto. de Contabilidade e Atuária da FEA-USP

E-mail: arisanto@usp.br

\section{RESUMO}

A contabilidade, como veículo de informação, tem como um de seus grandes desafios colocar à disposição de seus usuários informações que retratem as relações das empresas com a sociedade. $O$ Balanço Social, no todo, e a Demonstração do Valor Adicionado - DVA - como uma de suas vertentes, se apresentam como os instrumentos capazes de evidenciar tanto os aspectos econômicos, quanto os sociais, inovando o enfoque utilizado até então, e se constituindo nas mais ricas demonstrações para aferição dessas relações. Dessa forma, o principal objetivo deste estudo foi a realização de uma pesquisa junto a 416 empresas, retiradas do cadastro mantido pela FIPECAFI para a edição anual de MeIhores e Maiores da Revista EXAME. Nesta pesquisa, procurou-se avaliar o poder de aferição representado pela DVA no que concerne a informações sobre a formação de riqueza pelas empresas e sua distribuição aos agentes econômicos que ajudaram a criá-la, como proprietários, sócios e acionistas, governo, financiadores externos e empregados. Ao final do estudo, tornou-se possível afirmar que os indicadores retirados da DVA se constituem num excelente avaliador da distribuição da riqueza, à disposição da sociedade, no entanto, sem nenhuma pretensão de substituir outros indicadores de riqueza já existentes, ou, até mesmo, rivalizar com eles.

Palavras-chave: Demonstração do Valor Adicionado; Sociedade; Participação de Empregados; Governo; Empresas; Carga Tributária.

\section{ABSTRACT}

As an information vehicle, Accounting faces the task of making available information about the relations between companies and society to its users as one of its great challenges. The Social Balance Sheet in general and the Statement of Value Added - SVA - as one of its complements appear as instruments capable of demonstrating economic as well as social aspects, thus innovating on the traditional focus, which turns them into the richest statements for verifying these relations. Hence, a research was carried out in 416 companies that were taken from Fipecafi's "Melhores e Maiores" database for the Magazine Exame. This survey aimed to evaluate the SVA's verification power with respect to information about companies' wealth formation and its distribution to those economic agents that helped to create it, such as proprietors, partners and shareholders, government, external financiers and employees. At the end of the study, it could be affirmed that the indicators taken from the SVA make up an excellent means of evaluating wealth distribution, which is available to society, although without any intent of replacing or even competing with other existing wealth indicators.

Keywords: Statement of Value Added; Society; Employee Participation; Government; Companies; Tax Burden. 


\section{INTRODUÇÃO}

Pode-se afirmar que a contabilidade possui três grandes desafios: a identificação, a mensuração e a comunicação dos atos e fatos ocorridos em uma entidade.

O desafio em se comunicar, até então, vem sendo resolvido por meio da elaboração e divulgação das demonstrações contábeis ditas tradicionais, como: Balanço Patrimonial (BP), Demonstração do Resultado do Exercício (DRE), Demonstração das Origens e Aplicações de Recursos (Doar), Demonstração das Mutações do Patrimônio Líquido (Dmpl) e Notas Explicativas.

É por meio dessas demonstrações que as necessidades da maioria dos usuários da contabilidade, bem ou mal, vêm sendo atendidas, sejam eles sócios ou acionistas, fornecedores e financiadores, governo, administradores e empregados.

Esses últimos, entretanto, nunca obtiveram, por meio das demonstrações contábeis citadas, informações sobre suas próprias condições de trabaIho, como higiene, segurança e salubridade, e sobre o peso de sua remuneração e respectivos encargos sociais, dentro do universo de agentes econômicos que colaboram para que a empresa atinja seu objetivo de gerar riqueza.

Também, a comunidade, em que a entidade está inserida, e a sociedade de uma forma geral, jamais puderam contar com informações que as ajudassem a avaliar as vantagens e desvantagens em acolher essas entidades.

Nesse sentido e principalmente com o surgimento de movimentos sociais iniciados na França, Alemanha e Inglaterra na década de 60 , as exigências da sociedade em relação à cobrança de responsabilidade social por parte das empresas se tornaram mais intensas.

Essas exigências culminaram com a adoção pela França, no ano de 1977, do chamado Balanço Social, de forma obrigatória para as empresas com 300 empregados ou mais.

\subsection{Objetivos}

O objetivo deste estudo foi a avaliação do poder de aferição da DVA, no que concerne a informações sobre a formação de riqueza pelas empresas e sua distribuição aos agentes econômicos que ajudaram a criá-la, como proprietários, sócios e acionistas, governo, financiadores externos e empregados.

\subsection{Metodologia da Pesquisa}

Neste trabalho, pelas suas características, é utilizada uma abordagem Empírico-Analítica que, segundo Martins (2000, p. 26):

[...] são abordagens que apresentam em comum a utilização de técnicas de coleta, tratamento e análise de dados marcadamente quantitativos. Privilegiam estudos práticos. Suas propostas têm caráter técnico, restaurador e incrementalista. Têm forte preocupação causal entre variáveis. A validação da prova científica é buscada através de testes dos instrumentos, graus de significância e sistematização das definições operacionais.

Constitui-se de uma primeira parte em que é feita a fundamentação teórica com a utilização da técnica de pesquisa bibliográfica. Num segundo momento, são utilizados dados secundários, obtidos juntos à FIPECAFI, para a realização da pesquisa empírica.

\section{BALANÇO SOCIAL}

O Balanço Social é o instrumental que a contabilidade coloca à disposição da sociedade para demonstrar suas relações com a empresa. Num mesmo documento, evidencia tanto os aspectos econômicos quanto sociais, inovando, com isso, o enfoque usado até agora, em que a preocupação era basicamente com o capital. Para Tinoco (1984, p. 45):

O Balanço Social tem por ambição descrever uma certa realidade econômica e social de uma entidade, através do qual é suscetível de avaliação.

Em decorrência dele as relações entre o fator capital e o fator trabalho podem ser melhor regulados e harmonizados, na medida em que as forças sociais avancem e tomem posição, especialmente nos países de Terceiro Mundo, entre eles o Brasil, onde se observa a ocorrência de um capitalismo selvagem.

Nos países onde o capitalismo está mais desenvolvido várias empresas já vêm consagrando o balanço social como instrumento de gestão e de informação. Essas empresas divulgam normalmente informação econômica e social a seus trabalhadores, pois sua estrutura não é posta em causa, sendo o lucro aceito como uma vocação normal da empresa, permitindo que a relação entre dirigentes e assalariados torne-se consensual e não conflituosa.

Entretanto, diferentemente do que sentencia Tinoco, o que se observa é que nos países, em que o capitalismo está mais desenvolvido, as disputas 
econômicas são as mesmas, e o Balanço Social, quando utilizado, configura-se, apenas, como um instrumento de informações de recursos humanos e não de gestão.

Dentre as vertentes do Balanço Social, destaca-se a Demonstração do Valor Adicionado (DVA), que produz informações referentes à riqueza gerada pela empresa e a forma como foi feita sua distribuição aos agentes econômicos que ajudaram a produzi-la: os empregados, o governo, e os detentores de capitais, sócios, acionistas e financiadores externos.

Enquanto em alguns países do mundo não é sequer permitido que uma empresa se estabeleça em seu solo sem que apresente a DVA, no Brasil ela é pouco conhecida e divulgada, possivelmente por não se tratar, ainda, de uma demonstração obrigatória.

\section{DEMONSTRAÇÃO DO VALOR ADICIONADO}

Conceitualmente, a Demonstração do Valor Adicionado (DVA) é uma das peças formadoras do Balanço Social, mas em muitos casos o que se vê é sua apresentação dissociada dele e em conjunto com as outras Demonstrações Contábeis usuais, ou ainda, como o próprio Balanço Social.

Para De Luca (1998, p. 28), "A Demonstração do Valor Adicionado (DVA) é um conjunto de informações de natureza econômica. É um relatório contábil que visa demonstrar o valor da riqueza gerada pela empresa e a distribuição para os elementos que contribuíram para sua geração."

Estabelecendo um paralelo com o conceito de valor adicionado utilizado pelo segmento econômico, Kroetz (2000, p. 42) comenta:

Por meio da Demonstração do Valor Agregado é possível perceber a contribuição econômica da entidade para cada segmento com o qual ela se relaciona, constituindo-se no Produto Interno Bruto (PIB), produzido pela organização.

Ou seja, a demonstração do valor adicionado evidencia a riqueza que foi gerada, individualmente, por uma entidade.

E, ainda, dentro da mesma visão, Santos e Lustosa (1998, p. 4) avaliam:

A distribuição do valor adicionado equivale ao conceito macroeconômico de Renda Nacional. A transformação de recursos intermediários em produtos e serviços finais só é possível pelo emprego dos fatores de produção (trabalho, capital, governo, empresa). Em termos gerais, a remuneração destes fatores (salário, juro, aluguel, imposto e lucro) pelas empresas constitui a renda em poder da sociedade, que retorna às empresas tanto na aquisição de seus produtos e serviços como sob a forma de novos financiamentos, reiniciando o ciclo econômico.

Trata-se, pois, de um relatório contábil, que demonstra tanto os benefícios que as organizações oferecem para a sociedade, por meio, por exemplo, da absorção da mão-de-obra da comunidade em que estão inseridas, quanto a sua capacidade de gerar riqueza para a economia, ou seja, contribuir para o desenvolvimento econômico.

Mas não é apenas isso. A DVA permite, além da identificação da riqueza gerada exclusivamente pela empresa, a identificação daquela riqueza recebida em transferência, apresentando, ainda, um mapeamento de como essas riquezas são distribuídas aos seus diversos beneficiários: empregados, governo, financiadores externos e sócios ou acionistas.

Há autores que colocam em dúvida o potencial social das informações contidas na demonstração, como, por exemplo, Freire e Rebouças (2001, p. 105): "A DVA pode ser um importante componente contábil do balanço social, mas apresenta informações que estão muito aquém daquelas que seriam necessárias para seu reconhecimento como balanço social".

De fato, as informações prestadas pela DVA estão aquém daquelas prestadas pelo balanço social, porém, nunca teve pretensões de ser o próprio, mas apenas de compô-lo, como é destacado por Santos (1999, p. 98):

A Demonstração do Valor Adicionado, componente importantíssimo do balanço social, deve ser entendida como a forma mais competente criada pela contabilidade para auxiliar na medição e demonstração da capacidade de geração, bem como de distribuição, da riqueza de uma entidade.

Uma empresa, normalmente, tem capacidade de geração de riqueza bem maior do que o lucro que distribui aos seus sócios ou acionistas. Tradicionalmente, o lucro obtido pela empresa tem sido apresentado por meio da Demonstração do Resultado do Exercício - DRE. Para ludícibus, Martins e Gelbcke (2000, p. 290), "A Demonstração do Resultado do Exercício é a representação, em forma resumida, das operações realizadas pela empresa, durante o exercício social, demonstradas de forma a destacar o resultado líquido do exercício." Entre- 
tanto, essa demonstração não analisa a contribuição dos agentes econômicos na geração da riqueza da empresa e, por isso, não evidencia a parcela que tocou a cada um deles no processo produtivo, pois está voltada para a apuração e divulgação do lucro, que pertence ao proprietário.

Santos (1999, p. 20), discorrendo sobre a visão particular do lucro na Demonstração do Resultado do Exercício, conclui:

Nesse aspecto, a Demonstração do Valor Adicionado - DVA - é muito mais abrangente, pois não está exclusivamente voltada para a apuração do resultado, porquanto considera outros fatores de produção e aponta suas respectivas remunerações. São componentes dessa demonstração, além da informação relativa à riqueza gerada pela empresa, a forma com que essa riqueza é distribuída através de impostos pagos ao governo, juros e aluguéis destinados a financiadores externos, remunerações pagas aos trabalhadores e lucros e dividendos (ou juros sobre o capital próprio, como previsto na legislação brasileira) atribuídos aos proprietários, sócios e acionistas.

Entretanto, na avaliação do autor acima citado (2001, p. 3), DRE e DVA são demonstrações que se complementam, tratando, inclusive, dos mesmos itens, apenas com enfoques diferentes. A DRE, por exemplo, trata juros, salários e outros, como despesas e/ou custos da empresa para gerar receitas, o que na visão do proprietário diminui seu lucro, enquanto na DVA esses itens representam a forma pela qual os beneficiários da riqueza receberam a sua parcela.

Conforme Cunha (2002, p. 44):

A Demonstração do Valor Adicionado representa um novo rumo em comparação com as Demonstrações Contábeis tradicionais, pois enquanto estas têm como foco principal de preocupação a evidenciação das informações sobre o lucro e sua forma de apuração, para os investidores, aquela mostra, além do lucro dos investidores, a quem pertence a outra parte da riqueza gerada pela empresa, refletindo, ainda, uma preocupação empresarial que é nova, e baseada na responsabilidade social, a remuneração dos fatores de produção que ajudaram a formar a riqueza da organização.

Dessa forma, torna-se possível uma melhor avaliação do conjunto de empresas formadoras de uma sociedade. Os Valores Adicionados por elas, calculados por meio da DVA, constituem-se numa parte significativa de toda a riqueza gerada por um país. É, também, por meio da DVA que se pode mostrar e avaliar como essa riqueza está sendo distribuída por meio dos impostos pagos ao governo, lucros e dividendos aos acionistas, e ainda remunerações pagas aos trabalhadores, que é o foco deste estudo.

Parafraseando Ribeiro e Lisboa (1999, p. 2), em princípio, uma empresa só deveria ser autorizada a exercer suas atividades se o custo-benefício de sua existência para a sociedade se apresentasse positivo.

A DVA surgiu na Europa, há anos, apesar de ser encontrada, na literatura, referência sobre ela no tesouro americano no Século XVIII. Seu desenvolvimento foi impulsionado pela urgência na introdução do imposto sobre valor agregado nos países europeus, e, a partir do final dos anos 70, atingiu uma grande popularidade no Reino Unido, com a publicação do Corporate Report pelo Accounting Standards Steering Committee, atualmente Accounting Standards Committee, em agosto de 1975 (BELKAQUI apud CUNHA, 2002, p. 46). Esse relatório recomendava, dentre outras coisas, a elaboração da DVA, para evidenciar como os benefícios e os esforços de uma empresa são divididos pelos empregados, provedores de capital, Estado e reinvestimentos.

A recomendação foi aceita e uma das propostas do legislativo do Reino Unido, contidas no relatório The future of company reports, de 1977, foi para a DVA.

A DVA veio, então, se juntar ao balanço patrimonial, à demonstração de resultados e às outras demonstrações contábeis.

Cresce, assim, o número de companhias que, a cada ano, elaboram sua DVA. Uma pesquisa realizada em 1980 relatou que mais de 1/5 das grandes companhias do Reino Unido divulgam esse relatório (BELKAQUI apud CUNHA, 2002, p. 46). Esse aumento, também, pode ser creditado aos esforços empreendidos pelas associações de trabalhadores, que estimularam o crescimento do número de relatórios, por verem nele um bom veículo para evidenciar a informação e uma base para determinar salários e remunerações.

Como a DVA evidencia a geração de riqueza pela empresa e sua forma de distribuição aos agentes que colaboraram na sua criação, constitui-se numa visão nova para os trabalhadores sobre o desempenho das entidades. Por meio dessa demonstração, é possível aos trabalhadores avaliarem a oscilação da riqueza que a empresa produziu, acompanhar a parcela que está sendo levada por 
eles e, assim, conscientemente, lutar por aumentos reais de salários e de incentivos, em virtude desse acréscimo na riqueza.

Foi durante o crescimento de popularidade, acontecido nos anos 70, que a DVA foi considerada, em muitos países europeus, como uma das ferramentas centrais para a divulgação de informações tidas como relevantes para a sociedade. Não somente os acadêmicos, mas especialmente os comitês e institutos contábeis, passaram, então, a preocupa-se com as proposições para a apresentação da DVA (CUNHA, 2002, p. 48).

Em vários países da África e também na Índia, a DVA é considerada um relatório com informações tão relevantes que é exigida sua apresentação de qualquer empresa que queira se instalar em seu território, para avaliar quanta riqueza ela é capaz de criar dentro do país. Para eles, pouco adianta quem vende muito, mas compra muito (a exemplo de algumas montadoras de automóveis), pois está gerando pouca riqueza nova (MARTINS, 1997d, p. 4-5).

No Brasil, a lei societária que vigora atualmente - Lei 6.404 de 15 de dezembro de 1.976, e que dispõe sobre as sociedades por ações - não contempla a divulgação da demonstração do valor adicionado.

No entanto, a partir das discussões sobre a responsabilidade social das empresas e sua prestação de contas para a sociedade, as empresas brasileiras passaram a sentir a importância do cálculo e da divulgação do valor adicionado e de sua distribuição. Seja por assumirem a responsabilidade social que Ihes era embutida, seja por cobranças da própria sociedade ou, ainda, como forma de marketing.

Fato é que se encontra na Câmara dos Deputados, o Projeto de Lei . $^{\circ} 3.741 / 2000$, de autoria do Poder Executivo, que altera e revoga dispositivos da Lei 6.404/76 - a Lei das Sociedades por Ações. Dentre outras alterações previstas, o artigo 176 passará a vigorar com a seguinte redação:

Art. 176 - Ao fim de cada exercício social, a diretoria da companhia fará elaborar, com base na escrituração mercantil, as seguintes demonstrações contábeis, que deverão exprimir com clareza a situação patrimonial e financeira e as mutações ocorridas no exercício:

II - demonstrações do patrimônio líquido;

IV - demonstrações dos fluxos de caixa; e

$\mathrm{V}$ - demonstração do valor adicionado.

Além de incluir a DVA entre as demonstrações contábeis de elaboração obrigatória, o Projeto de
Lei estende às sociedades de grande porte essa obrigatoriedade, mesmo quando não constituídas sob a forma de sociedades por ação. São consideradas de grande porte as sociedades ou conjunto delas - que façam parte de um mesmo grupo ou que estejam sob controle comum - que possuírem, no exercício social anterior, ativo acima de $120 \mathrm{mi}-$ Ihões de reais ou receita bruta anual acima de 150 milhões de reais, conforme o artigo segundo do projeto de lei 3.741/2000.

Nos meios acadêmicos, desde o ano de 1989, com a publicação do primeiro artigo sobre o assunto (MARTINS, 1989, p. 4), o Prof. Eliseu Martins, da Faculdade de Economia, Administração e Contabilidade da Universidade de São Paulo - FEA/USP, vem incentivando as discussões e pesquisas sobre o cálculo e divulgação da geração e distribuição da riqueza das empresas por meio da DVA. Desde então, o número de empresas que publicam essa demonstração vem aumentando.

Conforme informações do próprio Martins (1997b, p. 1), a empresa Mappin Lojas de Departamentos S/A, controlada da companhia de capital aberto Casa Anglo Brasileira S/A, foi a primeira empresa brasileira a divulgar, referente ao ano de 1994, a DVA como nota explicativa de suas demonstrações contábeis, a nota de número 18 . Até então, as demais empresas que vinham divulgando essa demonstração, faziam-no dentro do relatório da administração, a exemplo do Banco Itaú.

\section{A PESQUISA}

No ano de 1997 (SANTOS, 1999, p. 56-57), os Profs. Ariovaldo dos Santos e L. Nelson de CarvaIho, também da FEA/USP, responsáveis pela edição de Melhores e Maiores - MM - da Revista EXAME, bastante respeitada nos meios empresariais e acadêmicos, que analisa e lista, anualmente, as 500 Melhores e Maiores empresas do ano, mediante critérios próprios e objetivos de domínio público, publicaram dois artigos intitulados "Balanço Social, um indicador de excelência" e "DVA, uma forma de avaliar a criação de riqueza", destacando a grande importância das informações sociais e a utilidade da DVA.

A partir da edição de MM de 1998, dados relativos à DVA passaram a fazer parte desse critério de avaliação, denominado "excelência empresarial". Para tanto, foi desenvolvido na Fundação Instituto de Pesquisas Contábeis, Atuariais e Financeiras FIPECAFI, um modelo de DVA, para distribuição entre as empresas constantes do cadastro usado para a edição anual da $\mathrm{MM}$, juntamente com as instruções de preenchimento. Esse modelo passou 
a ser usado como padrão por aquelas empresas que enviavam suas informações para participar do ranking da $\mathrm{MM}$, e por muitas outras.

A FIPECAFI, nos últimos cinco anos, recebeu 940 DVAs relativas ao ano de 1999, 1.069 ao ano de 2000, 1.012 ao ano de 2001, 1.087 ao ano de 2002, e 1.147 ao ano de 2003. Das demonstrações recebidas pela FIPECAFI foram publicadas: 101 relativas ao ano de 2003, 102 ao ano de 2002, 96 ao ano de 2001, 87 ao ano de 2000 e 74 ao ano de 1999.

O universo representado pelas empresas que enviaram suas DVAs referentes aos anos de 1999 a 2003 constituiu-se na população escolhida para esta pesquisa.

\subsection{AMOSTRAGEM}

A composição da amostra foi elaborada pelo método não probabilístico, sendo usada a amostragem intencional. Martins (2000, p. 41) refere-se a tal tipo de amostragem da seguinte forma: "de acordo com determinado critério, é escolhido intencionalmente um grupo de elementos que irão compor a amostra". Assim, foram escolhidas 416 empresas que, ao longo do período analisado, 1999 a 2003, disponibilizaram em todos os cinco anos as referidas demonstrações.

Os valores das demonstrações apresentadas, nesta pesquisa, estão expressos em moeda do dia 31 de dezembro de 2003, sendo que a paridade utilizada para a transformação foi de $R \$ 2,8892$ para cada US $\$ 1.00$. Antes de serem convertidos para dólar, os valores referentes a pessoal e encargos, impostos, taxas e contribuições, juros e aluguéis e receita operacional bruta, foram atualizados pelo IGP-M - Índice Geral de Preços de Mercado, da Fundação Getúlio Vargas - até o último dia de cada ano. Exceção foi feita às empresas que apresentaram sua DVA em moeda de poder aquisitivo constante.

O número de empregados refere-se ao existente no último dia de cada um dos anos, e o número médio de empregados foi obtido pela média aritmética do número de empregados existentes no início e no final de cada ano. As referências e comparações, neste trabalho, com o Produto Interno Bruto - PIB são sempre em relação àquele que é calculado e divulgado pelo Instituto Brasileiro de Geografia e Estatística - IBGE.

\section{ANÁLISE DOS RESULTADOS}

A análise, que ora se procederá, tem pretensões apenas descritivas e exploratórias, não servindo as constatações encontradas na amostra para realizar qualquer inferência relativa à população. Isso se deve, principalmente, ao fato de tratar-se de amostra não probabilística. Além disso, cabe ressaltar que o estudo realizado pode ter sofrido algum viés, posto que a amostra é diversificada, apresentando empresas com dados bastante diferentes. Mesmo assim, optou-se por utilizar o conjunto, devido à grande oportunidade de análise de uma demonstração cuja elaboração é opcional e cresceu significativamente, nos últimos cinco anos.

\subsection{Análise Geral}

A amostra, que conta com 416 empresas que apresentaram a DVA em todos os cinco anos abrangidos pela pesquisa, foi agrupada por ramos de atividade e por setores. Segundo o ramo de atividade, foram encontradas e analisadas 59 empresas comerciais, representando $14,2 \%$ do total da amostra, 242 empresas industriais, ou 58,2\%, e 115 empresas prestadoras de serviço, 27,6\%.

Das empresas comerciais, 35 pertencem ao setor de atacado e comércio exterior e 24 ao de comércio varejista. As empresas industriais foram distribuídas pelos setores de: alimentos (30), automotivo (10), bebidas (5), confecções e têxteis (17), construção (17), diversos (5), eletroeletrônicos (13), farmacêutico, higiene e cosméticos (7), fumo (2), limpeza (3), material de construção (22), mecânica (8), mineração (14), papel e celulose (16), plásticos e borracha (9), química e petroquímica (34), e siderurgia e metalurgia (30). As empresas prestadoras de serviços foram divididas entre os setores de comunicação, serviços de transporte, serviços diversos, serviços públicos, tecnologia e computação, e telecomunicações com 4, 20, 14, 63, 9 e 5 empresas, respectivamente.

O montante do valor adicionado das $416 \mathrm{em}$ presas, expresso em moeda do dia 31 de dezembro de 2003 , no ano de 1999 , foi de 80,5 bilhões de dólares. Em 2000, 81,7 bilhões de dólares. Em 2001, montou a 90,1 bilhões de dólares. Para 2002, foi de 99,2 bilhões de dólares. Em 2003, o valor adicionado total chegou a 88,9 bilhões de dólares. Esses valores representam 14,4\%, 14,3\%, $15,9 \%, 19,6 \%$ e $17,0 \%$ do PIB, respectivamente. A distribuição da riqueza criada por essas empresas aos agentes que contribuíram para sua formação está na Tabela 1.

Observa-se que, de 2000 a 2003, o governo, através dos impostos recolhidos pelas empresas, ocupou o primeiro lugar na distribuição da riqueza criada. Nesse mesmo período, juros e aluguéis estiveram em segundo lugar. Em 1999, juros e aluguéis, destinados aos financiadores externos, ocuparam 
Tabela 1 - Distribuição do Valor Adicionado - em \% - 1999 a 2003

\begin{tabular}{c|c|c|c|c|c}
\hline Ano/Agente & Governo & Empregados & Sócios e Acionistas & Juros e Aluguéis & Lucros Retidos \\
\hline 1999 & 37,0 & 20,1 & 4,7 & 38,7 & $-0,5$ \\
\hline 2000 & 44,4 & 18,6 & 8,1 & 18,9 & 10,0 \\
\hline 2001 & 43,2 & 16,5 & 7,6 & 26,0 & 6,7 \\
\hline 2002 & 41,2 & 15,4 & 4,9 & 40,5 & $-2,0$ \\
\hline 2003 & 48,5 & 14,9 & 8,4 & 15,6 & 12,6 \\
\hline
\end{tabular}

Fonte: Elaborada pelos autores.

o primeiro lugar na distribuição da riqueza criada e isso foi fortemente influenciado pela desvalorização cambial ocorrida no ano.

O número médio de empregados das empresas da amostra em cada ano está no Gráfico 1. Essa média foi encontrada tomando-se por base o número de empregados existentes no início e no final do período, considerando-se, no início do período, o registro existente no último dia do período imedia-



Fonte: Elaborado pelos autores.

\section{Gráfico 1 - Número médio de empregados de 1999 a 2003}

das despesas com pessoal por empregado teve um forte declínio, caindo de 17,1 para 12,8 mil dólares, o que representou uma redução de $25,2 \%$.

A tabela 2 apresenta um grande conjunto de informações relativo à amostra de 416 empresas. tamente anterior. No período 1999/2003, verifica-se que esse número teve um aumento crescente e atingiu $8,59 \%$.

O valor agregado distribuído a cada empregado foi obtido dividindo-se o valor distribuído para pessoal e encargos, pelo número médio de empregados, e está representado no Gráfico 2.

Como se pode observar pelo gráfico anterior, no período de 1999 a 2003, a participação média

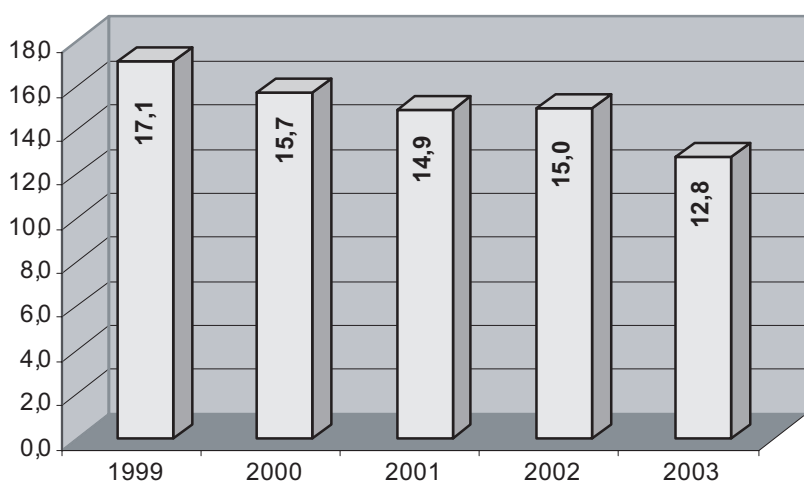

Fonte: Elaborado pelos autores.

\section{Gráfico 2 - Despesas com pessoal por empregado de 1999 a 2003 em US\$ mil}

O montante de riqueza criada pelas empresas constante da amostra apresentou-se ascendente até o ano de 2002, quando registrou 99,2 bilhões de

Tabela 2 - Informações Gerais

\begin{tabular}{|c|c|c|c|c|c|}
\hline \multirow[b]{3}{*}{ Informação } & & & & \multicolumn{2}{|c|}{ valores em US\$ milhões } \\
\hline & \multicolumn{5}{|c|}{ Amostra total - (416 empresas) } \\
\hline & 1999 & 2000 & 2001 & 2002 & 2003 \\
\hline Valor adicionado gerado - V A & $80.517,6$ & $81.746,4$ & $90.133,3$ & $99.153,2$ & $88.894,9$ \\
\hline Participação \% do V A no PIB & 14,5 & 14,3 & 16,0 & 19,6 & 17,0 \\
\hline
\end{tabular}




\begin{tabular}{|c|c|c|c|c|c|}
\hline \multirow[b]{3}{*}{ Informação } & \multicolumn{5}{|c|}{ valores em US\$ milhões } \\
\hline & \multicolumn{5}{|c|}{ Amostra total - (416 empresas) } \\
\hline & 1999 & 2000 & 2001 & 2002 & 2003 \\
\hline Participação \% do V A na receita & 47,7 & 44,0 & 44,5 & 48,1 & 44,2 \\
\hline \multicolumn{6}{|l|}{ Distribuição do V A } \\
\hline Pessoal e encargos & $16.195,9$ & $15.173,8$ & $14.842,2$ & $15.233,6$ & $13.210,7$ \\
\hline$\%$ no VA Total & 20,1 & 18,6 & 16,5 & 15,4 & 14,9 \\
\hline Impostos, taxas e contribuições & $29.831,3$ & $36.319,2$ & $38.974,6$ & $40.886,5$ & $43.125,3$ \\
\hline$\%$ no VA Total & 37,0 & 44,4 & 43,2 & 41,2 & 48,5 \\
\hline Juros e aluguéis & $31.177,4$ & $15.466,3$ & $23.456,9$ & $40.138,2$ & $13.878,8$ \\
\hline$\%$ no VA Total & 38,7 & 18,9 & 26,0 & 40,5 & 15,6 \\
\hline Juros s/ capital próprio e dividendos & $3.813,6$ & $6.596,5$ & $6.890,1$ & $4.885,1$ & $7.455,1$ \\
\hline$\%$ no VA Total & 4,7 & 8,1 & 7,6 & 4,9 & 8,4 \\
\hline Lucros/prejuízos retidos & $-500,6$ & $8.190,6$ & $5.969,5$ & $-1.990,2$ & $11.225,0$ \\
\hline$\%$ no VA Total & $-0,5$ & 10,0 & 6,7 & $-2,0$ & 12,6 \\
\hline Número médio de empregados & $948.761,0$ & $967.523,0$ & $998.296,0$ & $1.016 .720,0$ & $1.030 .274,0$ \\
\hline Despesas com pessoal por empregado (em US\$ mil) & 17,1 & 15,7 & 14,9 & 15,0 & 12,8 \\
\hline
\end{tabular}

Fonte: elaborada pelos autores.

dólares, 23,1\% superior ao ano de 1999, que é o início da série. Em 2003, em relação ao ano de 2002, houve uma queda na geração de valor adicionado, mas, ainda assim, o período 1999/2003 registrou acréscimo real de 10,4\%.

A parcela da riqueza destinada aos empregados, na forma de salários e encargos, caiu de 16,2 bilhões de dólares, em 1999, para 13,2 bilhões, em 2003, o que representou uma redução relativa de $18,4 \%$. Tal redução, aliada ao aumento do número médio de empregados provocou a diminuição total de $25,2 \%$, comentada anteriormente.

A participação percentual da carga tributária (recursos destinados ao governo na forma de impostos, taxas e contribuições) no valor adicionado total, sofreu oscilação significativa no período analisado. De 1999 a 2003, tal participação percentual, dentre as empresas pesquisadas, saiu de $37,0 \%$ para $48,5 \%$, com crescimento de 11,5 pontos percentuais. Exceção feita ao exercício de 1999, quando os resultados foram fortemente influenciados pela desvalorização cambial, a maior parcela da riqueza criada pelas empresas tem sido destinada ao governo. Outro destaque a ser feito na distribuição da riqueza criada pelas empresas é relativo à parcela destinada aos financiadores externos de capital, na forma de juros e aluguéis. No período analisado essa participação, que foi de 38,7\% em 1999, subiu para 40,5\% em 2002 e caiu para 15,6\% em 2003. De qualquer forma, mesmo com a oscilação apontada, deve-se destacar que os recursos destinados aos financiadores externos, na forma de juros e aluguéis, são sempre, significativamente superiores àqueles que são destinados aos financiadores internos de capital - juros sobre o capital próprio, dividendos e lucros retidos. Os valores em dólares tiveram comportamento semelhante.

Embora, em 25.03.99, a Medida Provisória 1818/99 tenha autorizado as pessoas jurídicas a registrarem, em conta do ativo diferido, o resultado líquido negativo decorrente do ajuste dos valores em reais de obrigações e créditos, feito em razão da variação nas taxas de câmbio ocorrida no primeiro trimestre de 1999, permitindo que o valor da despesa registrada como ativo fosse amortizado ao longo de quatro anos-calendário, a partir da data do diferimento, a FIPECAFI, ao receber as demonstrações e informações contábeis referentes a esse período, ajustou o resultado das empresas em seu cadastro, lançando toda essa variação cambial no seu resultado, e reconhecendo, integralmente, o efeito negativo em 1999. Essa ação foi realizada com o intuito de não ferir os princípios contábeis, que determinam que as perdas e os ganhos cambiais decorrentes da flutuação da moeda nacional em relação a moedas estrangeiras devem ser, como regra geral, reconhecidos como 
despesa ou receita, pelo regime de competência, com base nas taxas de câmbio em vigor na data de encerramento do balanço. Esse ajuste permite a comparabilidade de dados entre as diversas empresas, já que nem todas optaram pela contabilização da variação cambial como ativo diferido.

\subsection{Análise por Ramo de Atividade}

A tabela 3 foi dividida em ramos de atividade (comércio, indústria e serviços) e demonstra as quantidades médias, absolutas e relativas, de empregados utilizados na geração de riqueza das empresas componentes da amostra.
Da amostra utilizada, observa-se que o ramo que mais empregou foi o industrial. Com número crescente de empregados, a indústria foi responsável por, aproximadamente, metade do contingente analisado; no período, o crescimento foi de $12 \%$. O comércio, que também teve crescimento durante todo o período analisado, empregava, em 1999, 110.966 pessoas e em 2003, 136.519 , com acréscimo de $23 \%$. O ramo de serviços apresentou oscilação, acabou em 2003 com, praticamente, a mesma quantidade de empregados que tinha em 1999, mas sua participação relativa caiu de $40,3 \%$ para $37,1 \%$.

Na seqüência, o gráfico 3 apresenta as despesas com pessoal por empregado e por ramo de atividade.

Tabela 3 - Número médio de empregados e percentual de 1999 a 2003

\begin{tabular}{c|c|c|c|c|c|c}
\hline Ano / Ramo & Comércio & $\%$ & Indústria & $\%$ & Serviços & $\%$ \\
\hline 1999 & 110.966 & 11,7 & 455.114 & 48,0 & 382.681 & 40,3 \\
\hline 2000 & 121.373 & 12,5 & 471.316 & 48,7 & 374.834 & 38,7 \\
\hline 2001 & 127.109 & 12,7 & 494.908 & 49,6 & 376.279 & 37,7 \\
\hline 2002 & 129.881 & 12,8 & 504.416 & 49,6 & 382.423 & 37,6 \\
\hline 2003 & 136.519 & 13,3 & 511.047 & 49,6 & 382.708 & 37,1 \\
\hline
\end{tabular}

Fonte: Elaborada pelos autores.



Fonte: Elaborado pelos autores.

\section{Gráfico 3 - Despesas com pessoal por empregado de 1999 a 2003 - por ramo de atividade em US\$ mil}

O ramo que detém o maior valor adicionado distribuído por empregado ao longo do período é o de serviços, com a indústria ocupando a segunda colocação, e o comércio em último. Mas, deve-se observar que em todos os ramos esse valor está em declínio.
Um resumo com as principais informações por ramo de atividade se encontra nas tabelas a seguir. Pela observação da tabela 4, pode-se constatar que a riqueza criada pelo comércio durante o período analisado oscilou, mas apresentou uma redução de 2,7\% quando se compara 1999 e 2003. 
Tabela 4 - Informações Gerais - Comércio

\begin{tabular}{|c|c|c|c|c|c|}
\hline Informação (em US\$ milhões) & 1999 & 2000 & 2001 & 2002 & 2003 \\
\hline V A gerado & $4.840,3$ & $4.251,3$ & $5.011,6$ & $5.062,4$ & $4.708,4$ \\
\hline Participação \% do V A no PIB & 0,9 & 0,7 & 0,9 & 1,0 & 0,9 \\
\hline Participação \% do V A na receita & 17,3 & 14,5 & 15,7 & 15,6 & 14,5 \\
\hline \multicolumn{6}{|l|}{ Distribuição do V A } \\
\hline Pessoal e encargos & $1.076,9$ & $1.081,9$ & $1.066,2$ & $1.049,7$ & $1.034,4$ \\
\hline$\%$ no VA Total & 22,2 & 25,4 & 21,3 & 20,7 & 22,0 \\
\hline Impostos, taxas e contribuições & $2.353,6$ & $2.319,0$ & $2.358,8$ & $2.510,2$ & $2.276,9$ \\
\hline$\%$ no VA Total & 48,6 & 54,5 & 47,1 & 49,6 & 48,4 \\
\hline Juros e aluguéis & $1.123,9$ & 747,9 & 782,8 & 963,6 & 744,0 \\
\hline$\%$ no VA Total & 23,2 & 17,6 & 15,6 & 19,0 & 15,8 \\
\hline Juros s/ capital próprio e dividendos & 159,2 & 136,5 & 151,9 & 238,2 & 250,1 \\
\hline$\%$ no VA Total & 3,3 & 3,2 & 3,0 & 4,7 & 5,3 \\
\hline Lucros/prejuízos retidos & 126,7 & $(34,0)$ & 651,9 & 300,7 & 403,0 \\
\hline$\%$ no VA Total & 2,7 & $(0,7)$ & 13,0 & 6,0 & 8,5 \\
\hline Número médio de empregados & $110.966,0$ & $121.373,0$ & $127.109,0$ & $129.881,0$ & $136.519,0$ \\
\hline Despesas com pessoal por empregado (em US\$ mil) & 9,7 & 8,9 & 8,4 & 8,1 & 7,6 \\
\hline
\end{tabular}

Fonte: Elaborada pelos autores.

A mesma situação foi observada no ramo de serviços, com uma variação negativa de 1999 para 2003 , de $1,7 \%$, havendo, entretanto, duas oscila- ções positivas ao longo do período: 14,6\% de 2000 para 2001 e $4,5 \%$ de 2001 para 2002.

O ramo industrial teve comportamento distinto,

Tabela 5 - Informações Gerais - Serviço

\begin{tabular}{|c|c|c|c|c|c|}
\hline Informação (em US\$ milhões) & 1999 & 2000 & 2001 & 2002 & 2003 \\
\hline V A gerado & $27.414,3$ & $25.517,4$ & $29.251,5$ & $30.567,3$ & $26.942,9$ \\
\hline Participação \% do V A no PIB & 4,9 & 4,5 & 5,2 & 6,0 & 5,1 \\
\hline Participação \% do V A na receita & 55,0 & 49,2 & 50,2 & 55,5 & 56,0 \\
\hline \multicolumn{6}{|l|}{ Distribuição do V A } \\
\hline Pessoal e encargos & $7.411,7$ & $6.724,5$ & $6.220,6$ & $6.695,5$ & $5.202,5$ \\
\hline$\%$ no VA Total & 27,0 & 26,4 & 21,3 & 21,9 & 19,3 \\
\hline Impostos, taxas e contribuições & $9.093,8$ & $10.646,2$ & $11.047,2$ & $10.496,4$ & $11.672,5$ \\
\hline$\%$ no VA Total & 33,2 & 41,7 & 37,8 & 34,3 & 43,3 \\
\hline Juros e aluguéis & $11.454,5$ & $5.943,9$ & $10.042,9$ & $17.290,1$ & $6.345,9$ \\
\hline$\%$ no VA Total & 41,8 & 23,3 & 34,3 & 56,6 & 23,6 \\
\hline Juros s/ capital próprio e dividendos & 988,1 & $1.743,7$ & $1.777,4$ & $1.193,6$ & $1.777,3$ \\
\hline$\%$ no VA Total & 3,6 & 6,8 & 6,1 & 3,9 & 6,6 \\
\hline Lucros/prejuízos retidos & $(1.533,8)$ & 459,1 & 163,4 & $(5.108,3)$ & $1.944,7$ \\
\hline$\%$ no VA Total & $(5,6)$ & 1,8 & 0,5 & $(16,7)$ & 7,2 \\
\hline Número médio de empregados & $382.681,0$ & $374.834,0$ & $376.279,0$ & $382.423,0$ & $382.708,0$ \\
\hline Despesas com pessoal por empregado (em US\$ mil) & 19,4 & 17,9 & 16,5 & 17,5 & 13,6 \\
\hline
\end{tabular}

Fonte: Elaborada pelos autores. 
apresentando crescimento da riqueza gerada, entre 1999 e 2002, de 31,6\%. Em 2003, houve queda, em relação a 2002, de $9,9 \%$, mas, ainda assim, no período pesquisado o crescimento apresentado pela indústria foi de $18,6 \%$.
O ramo de serviços foi aquele que apresentou a melhor distribuição percentual para os empregados no período de 1999 a 2002. Em 2003 esse destaque ficou para o comércio, com $22,2 \%$ da riqueza criada sendo destinada para pessoal. O ramo de serviços,

Tabela 6 - Informações Gerais - Indústria

\begin{tabular}{|c|c|c|c|c|c|}
\hline Informação (em US\$ milhões) & 1999 & 2000 & 2001 & 2002 & 2003 \\
\hline V A gerado & $48.263,0$ & $51.977,7$ & $55.870,2$ & $63.523,5$ & $57.243,6$ \\
\hline Participação \% do V A no PIB & 8,7 & 9,1 & 9,9 & 12,5 & 10,9 \\
\hline Participação \% do V A na receita & 53,0 & 49,6 & 49,8 & 53,5 & 47,5 \\
\hline \multicolumn{6}{|l|}{ Distribuição do V A } \\
\hline Pessoal e encargos & $7.707,3$ & $7.367,4$ & $7.555,4$ & $7.488,4$ & $6.973,8$ \\
\hline$\%$ no VA Total & 16,0 & 14,2 & 13,5 & 11,8 & 12,2 \\
\hline Impostos, taxas e contribuições & $18.383,9$ & $23.354,0$ & $25.568,6$ & $27.879,9$ & $29.175,9$ \\
\hline$\%$ no VA Total & 38,1 & 44,9 & 45,8 & 43,9 & 51,0 \\
\hline Juros e aluguéis & $18.599,0$ & $8.774,5$ & $12.631,2$ & $21.884,5$ & $6.788,9$ \\
\hline$\%$ no VA Total & 38,5 & 16,9 & 22,6 & 34,5 & 11,9 \\
\hline Juros s/ capital próprio e dividendos & $2.666,3$ & $4.716,3$ & $4.960,8$ & $3.453,3$ & $5.427,7$ \\
\hline$\%$ no VA Total & 5,5 & 9,1 & 8,9 & 5,4 & 9,5 \\
\hline Lucros/prejuízos retidos & 906,5 & $7.765,5$ & $5.154,2$ & $2.817,4$ & $8.877,3$ \\
\hline$\%$ no VA Total & 1,9 & 14,9 & 9,2 & 4,4 & 15,4 \\
\hline Número médio de empregados & $455.114,0$ & $471.316,0$ & $494.908,0$ & $504.416,0$ & $511.047,0$ \\
\hline Despesas com pessoal por empregado (em US\$ mil) & 16,9 & 15,6 & 15,3 & 14,8 & 13,6 \\
\hline
\end{tabular}

Fonte: Elaborada pelos autores.

também, foi o que sofreu a maior perda relativa, no período 1999/2003, pois os valores destinados a pessoal caíram de $27,0 \%$ para $19,3 \%$. A segunda maior queda nos valores destinados a pessoal e encargos, nesse período, ficou para a indústria, que viu reduzida essa parcela de $16,0 \%$ para $12,2 \%$.

O comércio apresentou ligeiro aumento na distribuição percentual para os empregados, de 22,2\% em 1999 para 25,4\% em 2000, acréscimo de 14,41\%; no geral, manteve a mesma distribuição percentual de 1999 para 2003.

Quanto ao número médio de empregados, apenas as prestadoras de serviços não apresentaram variação significativa nos postos de trabalho, de 382.681 vagas em 1999 para 382.708 em 2003; a indústria ganhou 55.933 vagas e o comércio 25.553 , todas relativas ao período de 2003, comparadas ao de 1999.
Ao se analisar o valor distribuído a cada empregado, constatou-se: no comércio, queda de $21,7 \%$ de 1999 para 2003, conseqüência do decréscimo na distribuição em dólares para os empregados e do aumento no número de pessoas empregadas - mais empregados com menor remuneração.

$\mathrm{Na}$ indústria, queda de $19,5 \%$ no valor adicionado distribuído a cada empregado gerada pelo aumento de postos de trabalho e diminuição das despesas com pessoal e encargos.

No ramo de serviços, constatou-se a maior queda no valor distribuído a cada empregado, 29,9\% de 1999 a 2003 com número de vagas mantido mas distribuição em dólares decrescentes (29,8\% de 1999 para 2003).

No tocante à participação do governo na distribuição do valor adicionado, o único ramo que, 
praticamente, não teve alteração no percentual de participação e no valor em dólares foi o de comércio, de 48,6\% em 1999 (2,4 bilhões), para 48,4\% em 2003 (2,3 bilhões); a indústria apresentou aumento tanto na participação percentual, de $38,1 \%$ para $51,0 \%$, quanto no montante em dólares, de 18,4 bilhões para 29,2 bilhões; e as prestadoras de serviços, que apresentaram aumento na participação percentual, de $33,2 \%$ para $43,3 \%$, e acréscimo no valor em dólares de 9,09 bilhões para 11,7 bilhões, fruto do aumento na geração de riquezas.

Observe-o, também, que o ramo de serviços foi o que menos distribuiu riqueza para o governo, portanto, aquele com menor carga tributária.

\subsection{Análise por Setores}

Como dito anteriormente, a amostra utilizada, neste trabalho, é composta por demonstrações de 416 empresas, distribuídas em três ramos de atividade e vinte e cinco setores. Para alguns setores da amostra, a avaliação não será feita, pois estará pre- judicada uma vez que é composta por quantidades muito pequenas de empresas. Os setores de Fumo com 2 empresas, o de Limpeza com 3 empresas e o de Comunicações com 4 são exemplos dessa situação. Em faixas intermediárias, entre 5 e 15 empresas, existem 10 setores. São seis os setores nos quais a amostra totalizou entre 16 e 29 empresas. Os setores com quantidades mais significativas de empresas são os seguintes: Serviços Públicos, 63; Atacado e Comércio Exterior, 35; Química e Petroquímica, 34; Siderurgia e Metalurgia, 30 e o setor de Alimentos também com 30 empresas. Assim, a análise setorial estará restrita a esse conjunto em que as quantidades de DVAs disponíveis são mais significativas.

Esses cinco setores juntos agregam um conjunto de 192 empresas que representam $46 \%$ das 416 empresas analisadas anteriormente. A seguir, apresenta-se o Gráfico 4, no qual são comparadas as informações do conjunto de 416 empresas e as desse novo conjunto, com 192 empresas, relativo aos cinco setores citados anteriormente. Na seqüência, são

\section{DISTRIBUIÇÃO DO VALOR ADICIONADO $1999,2000,2001,2002$ e 2003 - em \%}

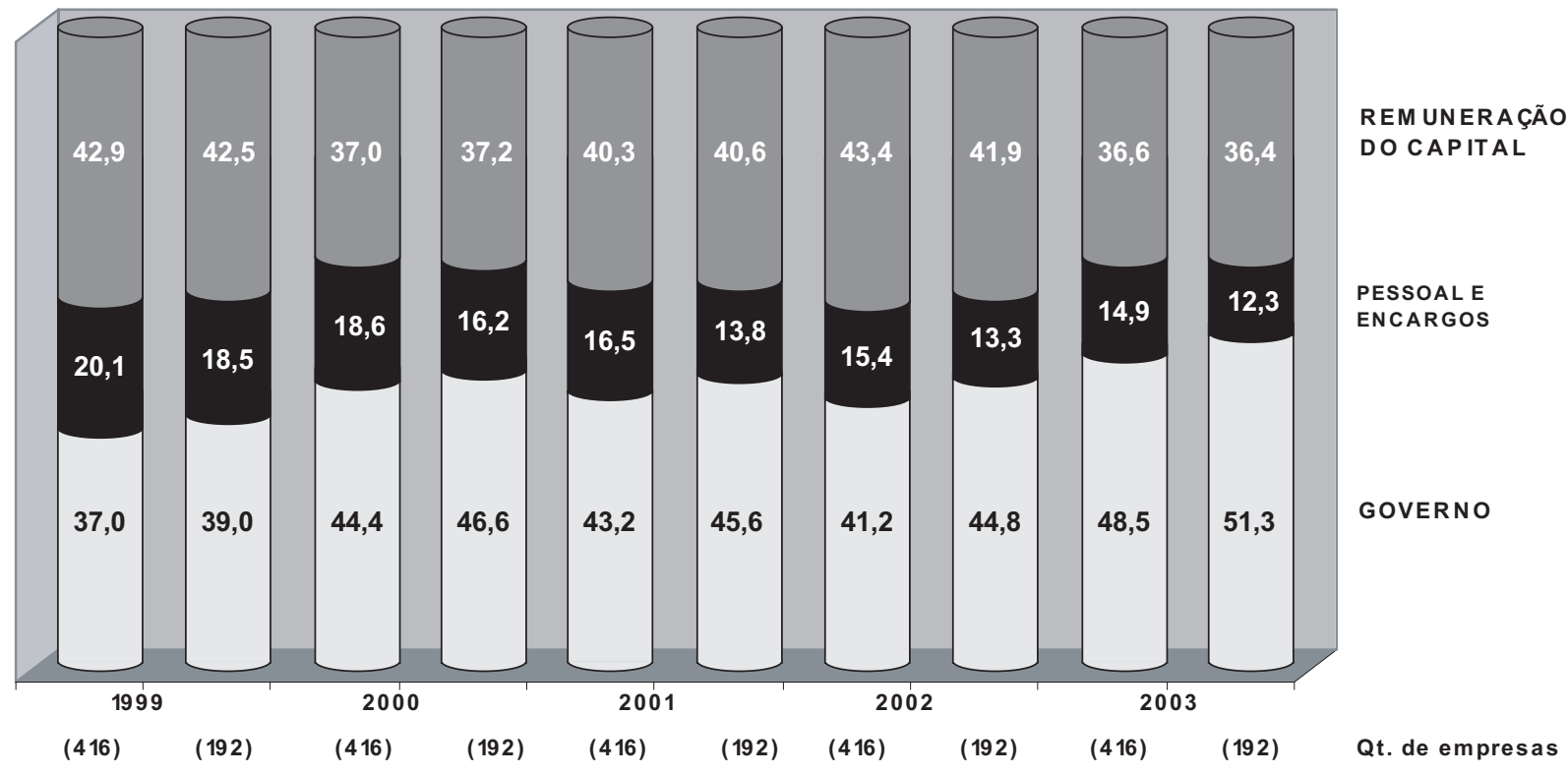

Fonte: Elaborado pelos autores.

\section{Gráfico 4 - Distribuição do Valor Adicionado}

apresentadas tabelas com informações de cada um dos cinco setores analisados e o respectivo total.
Como se pode ver, a comparação da amostra total (416 empresas), no que se refere à distribuição 
da riqueza, com o conjunto de cinco setores - 192 empresas - mostra pouquíssimas diferenças. A maior delas, em pontos percentuais, fica por conta da participação do Governo no ano de 2002. Nesse ano, o conjunto total das empresas da amostra teve carga tributária de $41,2 \%$, enquanto os cinco setores especificados anteriormente chegaram a $44,8 \%$, uma diferença de 3,6 pontos percentuais. Nessa comparação, entre as empresas da amostra total e o conjunto dos cinco setores analisados, o que mais chama a atenção é a diminuição da parcela da riqueza destinada a pessoal e encargos; em ambos os casos essa diminuição é bastante significativa. No período 1999/2003, os empregados das empresas da amostra total viram sua participação na riqueza criada cair de $20,1 \%$ para $14,9 \%$; nos cinco setores analisados a redução foi ainda maior, caiu de $18,5 \%$ para $12,3 \%$.

Tabela 7 - Distribuição do Valor Adicionado por Setor

\begin{tabular}{|c|c|c|c|c|c|}
\hline Serviços Públicos (63 empresas) & 1999 & 2000 & 2001 & 2002 & 2003 \\
\hline $\begin{array}{l}\text { Valor adicionado gerado } \\
\text { (em US\$ milhões de dez/2003) }\end{array}$ & $19.914,4$ & $17.798,1$ & $20.317,2$ & $21.057,9$ & $18.281,8$ \\
\hline \multicolumn{6}{|l|}{ Distribuição \% } \\
\hline Pessoal e encargos & 24,9 & 25,0 & 19,5 & 21,5 & ‘ 18,4 \\
\hline Impostos, taxas e contribuições & 33,4 & 43,0 & 37,3 & 33,3 & 44,4 \\
\hline Juros e aluguéis & 45,0 & 26,3 & 38,1 & 65,2 & 22,6 \\
\hline Juros s/ capital próprio e dividendos & 2,4 & 6,1 & 4,2 & 1,3 & 5,7 \\
\hline Lucro retido & $-5,7$ & $-0,4$ & 0,9 & $-21,3$ & 8,9 \\
\hline Atacado e Comércio Exterior (35 empresas) & 1999 & 2000 & 2001 & 2002 & 2003 \\
\hline $\begin{array}{l}\text { Valor adicionado gerado } \\
\text { (em US\$ milhões de dez/2003) }\end{array}$ & $3.034,6$ & 2. 573,4 & $3.204,1$ & $3.204,5$ & $3.044,8$ \\
\hline \multicolumn{6}{|l|}{ Distribuição \% } \\
\hline Pessoal e encargos & 17,0 & 19,6 & 15,5 & 16,1 & 16,8 \\
\hline Impostos, taxas e contribuições & 53,2 & 62,4 & 49,3 & 54,5 & 49,5 \\
\hline Juros e aluguéis & 24,0 & 16,1 & 12,7 & 14,2 & 15,9 \\
\hline Juros s/ capital próprio e dividendos & 3,9 & 4,2 & 4,0 & 5,7 & 7,0 \\
\hline Lucro retido & 1,9 & $-2,3$ & 18,5 & 9,5 & 10,8 \\
\hline Química e Petroquímica (34 empresas) & 1999 & 2000 & 2001 & 2002 & 2003 \\
\hline $\begin{array}{l}\text { Valor adicionado gerado } \\
\text { (em US\$ milhões de dez/2003) }\end{array}$ & $19.601,4$ & $24.596,0$ & $27.912,6$ & $31.180,3$ & $31.278,8$ \\
\hline \multicolumn{6}{|l|}{ Distribuição \% } \\
\hline Pessoal e encargos & 10,6 & 7,5 & 7,1 & 5,8 & 6,1 \\
\hline Impostos, taxas e contribuições & 47,7 & 53,7 & 55,7 & 59,7 & 61,2 \\
\hline Juros e aluguéis & 34,8 & 14,5 & 18,7 & 25,3 & 9,8 \\
\hline Juros s/ capital próprio e dividendos & 4,0 & 6,7 & 7,1 & 4,0 & 7,1 \\
\hline Lucro retido & 2,9 & 17,6 & 11,4 & 5,2 & 15,8 \\
\hline
\end{tabular}

Fonte: Elaborada pelos autores. 
Tabela 8 - Distribuição do Valor Adicionado por Setor

\begin{tabular}{|c|c|c|c|c|c|}
\hline Alimentos (30 empresas) & 1999 & 2000 & 2001 & 2002 & 2003 \\
\hline $\begin{array}{l}\text { Valor adicionado gerado } \\
\text { (em US\$ milhões de dez/2003) }\end{array}$ & $3.639,5$ & $2.560,3$ & $3.242,9$ & $3.735,0$ & $2.870,2$ \\
\hline \multicolumn{6}{|l|}{ Distribuição \% } \\
\hline Pessoal e encargos & 21,8 & 28,5 & 24,4 & 21,8 & 24,6 \\
\hline Impostos, taxas e contribuições & 25,2 & 39,1 & 35,3 & 30,1 & 39,9 \\
\hline Juros e aluguéis & 47,3 & 24,1 & 26,6 & 45,3 & 17,2 \\
\hline Juros s/ capital próprio e dividendos & 3,0 & 3,9 & 4,7 & 2,3 & 4,9 \\
\hline Lucro retido & 2,7 & 4,4 & 9,0 & 0,5 & 13,4 \\
\hline Siderurgia e Metalurgia (30 empresas) & 1999 & 2000 & 2001 & 2002 & 2003 \\
\hline $\begin{array}{l}\text { Valor adicionado gerado } \\
\text { (em US\$ milhões de dez/2003) }\end{array}$ & $6.236,2$ & $7.692,8$ & $6.891,1$ & $8.477,7$ & $7.891,9$ \\
\hline \multicolumn{6}{|l|}{ Distribuição \% } \\
\hline Pessoal e encargos & 22,1 & 17,8 & 18,4 & 15,8 & 16,3 \\
\hline Impostos, taxas e contribuições & 30,9 & 29,4 & 32,4 & 21,5 & 32,7 \\
\hline Juros e aluguéis & 47,3 & 21,0 & 35,6 & 54,3 & 15,7 \\
\hline Juros s/ capital próprio e dividendos & 3,8 & 13,1 & 7,6 & 4,0 & 11,9 \\
\hline Lucro retido & $-4,1$ & 18,7 & 6,0 & 4,4 & 23,4 \\
\hline Total (192 empresas) & 1999 & 2000 & 2001 & 2002 & 2003 \\
\hline $\begin{array}{l}\text { Valor adicionado gerado } \\
\text { (em US\$ milhões de dez/2003) }\end{array}$ & $52.426,1$ & $55.220,6$ & $61.567,9$ & $67.655,4$ & $63.367,5$ \\
\hline \multicolumn{6}{|l|}{ Distribuição \% } \\
\hline Pessoal e encargos & 18,5 & 16,2 & 13,8 & 13,3 & 12,3 \\
\hline Impostos, taxas e contribuições & 39,0 & 46,6 & 45,6 & 44,8 & 51,3 \\
\hline Juros e aluguéis & 40,4 & 19,7 & 27,1 & 41,9 & 14,8 \\
\hline Juros s/ capital próprio e dividendos & 3,3 & 7,1 & 5,9 & 3,2 & 7,2 \\
\hline Lucro retido & $-1,2$ & 10,4 & 7,6 & $-3,2$ & 14,4 \\
\hline
\end{tabular}

Fonte: Elaborada pelos autores.

Os dois setores com maiores cargas tributárias foram os de Atacado e Comércio Exterior e Química e Petroquímica. Nos anos de 1999 e 2000, o setor de atacado e Comércio Exterior liderou o ranking dos mais tributados com $53,2 \%$ e $62,4 \%$, respectivamente. Naqueles anos, o setor de Química e Petroquímica destinou ao governo, na forma de impostos, $47,7 \%$ e $53,7 \%$ da riqueza criada. Nos anos subseqüentes, 2001 a 2003, o setor de Química e Petroquímica passou a ser, dentro dos setores analisados, o que suportou a maior carga tributária.
Aqui vale ressaltar que os setores de Fumo e de Bebidas não estão sendo analisados individualmente, pois, mesmo com a alta incidência de impostos sobre seus produtos, não se conseguiu reunir em nossa amostra quantidade suficiente de demonstrações que pudessem suportar as conclusões.

As parcelas da riqueza criada destinada aos financiadores de capitais, externos e internos, tiveram comportamento irregular no que se refere à participação percentual, mas os valores destinados aos acionistas, na forma de juros sobre o capital 
próprio, dividendos e lucros retidos, foram sempre bastante inferiores àqueles que foram destinados aos emprestadores de capital na forma de juros e aluguéis.

\subsection{Análise por Regiões}

Conforme destacado por Santos (1999, p. 126), o ideal seria a realização de uma pesquisa que pudesse estudar as empresas da amostra em sua inserção regional, e, para tanto, dever-se-ia agrupá-las de acordo com a região geográfica a qual pertencessem.

Entretanto, para esse agrupamento tem-se o seguinte obstáculo: algumas empresas participantes da amostra, dentre elas Petrobras, Vale do Rio Doce e Souza Cruz, apesar de apresentarem sede em um Estado da Federação (nos casos citados, o Rio de Janeiro), se encontram espalhadas por diversos outros Estados e regiões do país.

As DVAs apresentadas por essas empresas para a elaboração da edição anual de $\mathrm{MM}$, e constante do cadastro da FIPECAFI, é única e centralizada pela sede.

Portanto, ao se estabelecer o valor adicionado criado e distribuído aos diversos agentes econômicos pelas empresas nas diversas regiões do país, trabalhar-se-ia com informação inexata. Apesar de os dados referentes a valor adicionado estarem sendo computados para um Estado ou região, poderiam ter sido gerados em outras localidades.

Dessa forma e por esse motivo, os dados existentes levarão a conclusões equivocadas, inexatas e até completamente erradas. Assim, não se procedeu à análise dos dados agrupados por regiões, análise que seria bastante proveitosa, mas que só poderia ser realizada se as empresas apresentassem suas DVAs detalhando as regiões em que as riquezas tivessem sido geradas e distribuídas.

\section{CONSIDERAÇÕES FINAIS}

Como foi divulgado ao longo deste trabalho, o Balanço Social é o instrumental que a contabilidade colocou à disposição de seus usuários, atendendo às exigências da sociedade por informações socioeconômicas que demonstrassem o grau de responsabilidade e envolvimento social das empresas.

Observou-se que, como o Balanço Social ainda não é obrigatório no Brasil, é apresentado, voluntariamente, por algumas empresas, umas com o intuito de apenas fornecer maiores informações aos seus usuários, outras com objetivos de marketing.

Com relação à DVA, foco específico deste estudo, percebeu-se que, apesar do número con- siderável de empresas que a envia ao cadastro da FIPECAFI, são poucas as que a divulgam para o conhecimento de toda a sociedade. De qualquer forma, foram divulgadas mais de uma centena de DVAs relativas ao ano de 2003 e isso representa um crescimento de aproximadamente $38 \%$, em relação ao ano de 1999; se for considerado que não há qualquer exigência legal e que no início dos anos 1990 essa demonstração era praticamente desconhecida, inclusive dos profissionais ligados à área de contabilidade, o avanço pode ser considerado bastante bom.

Apesar do esforço que vem sendo feito por entidades de classe, agremiações acadêmicas, e outros, muito ainda há que se fazer.

A DVA possibilita o conhecimento do quanto cada empresa criou de riqueza e como a distribuiu aos agentes econômicos que ajudaram a criá-la. Além de atender a um maior número de usuários, quando comparada à DRE, amplia o universo atingido pela contabilidade e tem a grande vantagem de ser facilmente lida e interpretada. Como mostrado, serve como um excelente instrumento de análise, principalmente quando a questão é comparativa. Por meio da DVA, consegue-se perceber como a riqueza criada foi distribuída aos agentes e quais deles ficaram com a maior parte dela, possibilitando, inclusive, avaliações sobre se esses são os agentes que mais colaboraram na sua criação. É o caso do governo, que sempre fica com parte substancial da riqueza gerada.

Resta, apenas, que essa demonstração se adapte às necessidades informativas dos usuários, sendo elaborada, por exemplo, de forma descentralizada, por Estados e regiões onde a empresa atua. Dessa forma, as informações prestadas serão de mais valia, podendo ser analisadas em conjunto com aquelas divulgadas pelo IBGE sobre a renda da população, por região. Conforme se salientou neste trabalho, apesar de existir a informação referente ao local de sede das empresas, não se pode considerá-la como a geradora de toda a riqueza criada, visto que as empresas possuem unidades em outros Estados da Federação. E, ainda, deveriam vir acrescidas de dados sobre o número de empregados existentes na empresa no início e final do período, a exemplo do que é solicitado pela FIPECAFI, para que se pudesse proceder ao acompanhamento dos postos de trabalho existentes.

Portanto, conclui-se que a DVA é mais que uma nova demonstração contábil que faz parte do balanço social, tendo força própria, pois contém informações que sozinhas são conclusivas e bastante úteis. E torna-se possível afirmar que os indicadores retirados dessa demonstração se constituem num 
excelente avaliador da distribuição da riqueza, à disposição da contabilidade, no entanto sem nenhuma pretensão em substituir outros indicadores de riqueza já existentes, ou até mesmo, rivalizar, com eles.

Mas, para atingir ao seu grande potencial é necessário que seja bem elaborada e bastante divulgada. Só, assim, ela poderá atender, de forma satisfatória, e principalmente servir como guia, a novos usuários, ou a antigos, que não contavam com informações específicas - como é o caso dos empregados e das comunidades onde as entidades estão inseridas.

A elaboração da DVA e, principalmente, sua divulgação podem ser, ainda, a oportunidade que a contabilidade tem para mostrar seu alcance e utilidade para aqueles que não a vêm assim. Serviria, desse modo, como instrumento de marketing para a própria ciência que a criou.

\section{REFERÊNCIAS BIBLIOGRÁFICAS}

BELKAOUI, Ahmed. The new environment in international accounting. Quorum Books, 1998.

BRASIL. Lei n. 6.404 de 15 de dezembro de 1976. Dispõe sobre as sociedades por ações.

BRASIL. Medida Provisória n. 1.818 de 25 de março de 1999. Estabelece normas para registro do resultado líquido negativo decorrente do ajuste dos valores em reais de obrigações e créditos, e dá outras providências.

BRASIL. Projeto de Lei n. 3.741 de 8 de novembro de 2000. Altera e revoga dispositivos da Lei 6.404 , de 15 de dezembro de 1976 , define e estende às sociedades de grande porte disposições relativas à elaboração e publicação de demonstrações contábeis e dispõe sobre os requisitos de qualificação de entidades de estudo e divulgação de princípios, normas e padrões de contabilidade e auditoria como Organização da Sociedade Civil de Interesse Público.

CUNHA, Jacqueline Veneroso Alves da. Demonstração contábil do valor adicionado - DVA - um instrumento de mensuração da distribuição da riqueza das empresas para os funcionários. 2002. Dissertação (Mestrado em Controladoria e Contabilidade) - Faculdade de Economia e Contabilidade da Universidade de São Paulo, São Paulo.

DE LUCA, Márcia Martins Mendes. Demonstração do valor adicionado: do cálculo da riqueza criada pela empresa ao valor do PIB. São Paulo: Atlas, 1998.

FREIRE, Fátima de Souza e REBOUÇAS, Tereza Raquel da Silva. Uma descrição suscinta do balanço social francês, português, belga e brasileiro. in: SILVA, Cesar Algusto e Tibúrcio e FREIRE, Fátima de Souza. Balanço Social Teoria e Prática. São Paulo: Atlas, 2001.

IUDíCIBUS, Sérgio de; MARTINS, Eliseu; GELBCKE, Ernesto Rubens. Manual de Contabilidade das Sociedades por Ações. 5 ed., São Paulo: Atlas, 2000.
KROETZ, César Eduardo Stevens. Balanço social, teoria e prática. São Paulo: Atlas, 2000.

MARTINS, Eliseu. Balanço social - idéia que merece permanecer. Gazeta Mercantil. São Paulo: 18 Set. 1997(a), Caderno A, p. 3.

Demonstração do valor adicionado - Alguns exemplos reais. $I O B$ informações objetivas. São Paulo: TC boletim 31/97. (b)

Uma nova demonstração contábil: a do valor adicionado. $I O B$ informações objetivas. São Paulo: TC boletim $11 / 89$.

Uma nova demonstração contábil no projeto de reforma da Lei das S.A.: a do valor adicionado. IOB Informações objetivas. São Paulo: TC boletim 29/97. (d)

MARTINS, Gilberto de Andrade. Manual para elaboração de monografias e dissertações. 2. ed. São Paulo: Atlas, 2000.

RIBEIRO, Maisa de Souza. Balanço social. Revista Brasileira de Contabilidade. Brasília: n. 115, 72-81, jan/fev. 1999.

; LISBOA, Lázaro Plácido. Balanço social: instrumento de divulgação da interação da empresa com a sociedade. In: Encontro da ANPAD, 23ㅇ, 1999, Rio de Janeiro. Anais[...], 1999.

SANTOS, Ariovaldo dos. Demonstração contábil do valor adicionado - DVA - Um instrumento para medição da geração e distribuição de riqueza das empresas. 1999. Tese de Livre Docência - Faculdade de Economia e Contabilidade da Universidade de São Paulo, São Paulo.

Demonstração de Resultados X Demonstração de Valor Adicionado. Anefac news. São Paulo, ano I, n. 02, 3-4, maio 2001.

; LUSTOSA, Paulo Roberto B. Proposta de um modelo de DVA - Demonstração do Valor Adicionado - adequado ao novo desenho institucional e mercantil do setor 
elétrico brasileiro. São Paulo: Fundação Instituto de Pesquisa Econômica - FIPE, 1998.

; PARMEZZANO, Cláudia Meca. Demonstração do valor adicionado - dois casos muito especiais. IOB informações objetivas. São Paulo: boletim TC 1/99.

SEMINÁRIO BALANÇO SOCIAL - UMA IDÉIA VIVA (3․ GRUPO). 1997, São Paulo. Apostila[...] São Paulo: JCA Treinamentos e FIPECAFI - FEA/USP, 1997.
TINOCO, João Eduardo Prudêncio. Balanço social - Uma abordagem sócio-econômica da contabilidade. 1984. Dissertação (Mestrado em Controladoria e Contabilidade) - Faculdade de Economia e Administração da Universidade de São Paulo, São Paulo.

NOTA:

Endereço dos autores:

FEA - USP - Campus Capital

Av. Prof. Luciano Gualberto, 908 - prédio 3

Cidade Universitária - São Paulo - SP - 05508-900

FEARP - USP - Campus Ribeirão Preto

Av. Bandeirantes, 3.900

Ribeirão Preto - SP - 14040-900 